HEART REVIEW

\title{
Emerging medical treatments for aortic stenosis: statins, angiotensin converting enzyme inhibitors, or both?
}

\author{
D E Newby, S J Cowell, N A Boon
}

Aortic stenosis is the most common adult heart valve condition seen in the Western world and its incidence continues to rise. No established disease modifying treatments retard progression of the stenotic process. Recent insights into the pathogenesis of calcific aortic stenosis suggest that the disease mimics atherosclerosis. The natural history and progression of calcific aortic stenosis are described with particular emphasis on new and emerging medical treatments that may modify the disease process. In particular, statins and angiotensin converting enzyme inhibitors appear to hold promise but definitive evidence from large clinical trials is awaited.

See end of article for authors' affiliations

Correspondence to

Professor David E Newby, Room SU314, Chancellor's Building, Royal Infirmary, 49 Little France Crescent, Edinburgh EH16 4SB, UK; d.e.newby@ed.ac.uk

Accepted 13 August 2005
A ortic stenosis is the most common adult heart valve condition seen in the Western world. It is predominantly due to "degenerative" calcific disease, although it can be a consequence of congenital disease such as a bicuspid aortic valve and rheumatic heart disease or of a rare metabolic disease such as ochronosis. Watchful waiting and the judicious use of aortic valve replacement surgery remains the mainstay of its management and treatment. We describe here the aetiology and natural history of calcific aortic stenosis and discuss the prospect of developing medical treatments that can modify the disease process.

\section{NATURAL HISTORY OF CALCIFIC AORTIC STENOSIS}

Calcific aortic stenosis has been recognised for over a century. Recently it has been suggested that aortic sclerosis may be the earliest manifestation of this disease process: sclerosis arising from the development of valvar calcific lesions that progress slowly over many years before ultimately causing aortic stenosis. ${ }^{1}$ The current prominence of calcific aortic valve disease probably results from increased human longevity associated with the declining prevalence of rheumatic fever.

Calcific aortic stenosis is a progressive condition, characterised by a long asymptomatic phase lasting several decades, followed by a shorter symptomatic phase usually associated with severe narrowing of the aortic valve orifice. The outlook for patients with asymptomatic disease is generally good but the prognosis changes dramatically with the onset of symptoms in association with severe outflow obstruction-a two year survival rate of about $50 \% .^{2}$
Heart 2006;92:729-734. doi: 10.1136/hrt.2005.066852

Despite the favourable outlook for patients with mild asymptomatic disease, the risk of cardiovascular events unrelated to the aortic valve disease is increased. Otto et al reported that patients with aortic sclerosis have a $50 \%$ increased risk of myocardial infarction and cardiovascular death even in the absence of significant outflow tract obstruction. The Helsinki aging study also indicated that patients with moderate to severe aortic stenosis were at an increased risk of all cause and cardiovascular death irrespective of associated symptoms. ${ }^{3}$

\section{PATHOLOGY OF CALCIFIC AORTIC STENOSIS}

Historically, calcific aortic stenosis has been attributed to prolonged "wear and tear" and age associated valve degeneration. However, recent evidence suggests that it may be the result of an active inflammatory process involving biochemical, humoral, and genetic factors.

Normal aortic valve leaflets appear smooth, thin, and opalescent, with clearly defined tissue layers and very few cells. Increasing age gives rise to thickening of the tips of the valve leaflets, with an increase in the number of adipose cells and thinning of tissue layers. ${ }^{4}$ Calcific aortic stenosis is characterised by leaflet thickening, with irregular nodular masses on the aortic aspect of the valve. Microscopic assessment of both mild and severely affected valves shows endothelial and basement membrane disruption, with underlying subendothelial thickening. The lesion itself contains disorganised collagen fibres, chronic inflammatory cells, lipids, extracellular bone matrix proteins, and bone mineral. ${ }^{4}$

The histological features described closely resemble those seen in atherosclerosis and are strongly suggestive of chronic inflammation (fig 1). The factors initiating the inflammatory process have not been identified but mechanical injury to the endothelium is thought to pave the way for subsequent inflammation. Indeed, the disease tends to affect the aortic surface of the leaflets and the non-coronary cusp that correspond to areas of low shear and high tensile stress. Congenitally bicuspid aortic valves are less efficient than tricuspid valves at distributing mechanical stress leading to the more rapid development of stenosis.

Abbreviations: $A C E$, angiotensin converting enzyme ASTRONOMER, aortic stenosis progression observation: measuring effect of rosuvastatin; LDL, low density lipoprotein; SALTIRE, Scottish aortic stenosis and lipid lowering therapy, impact on regression; SEAS, simvastatin and ezetimibe in aortic stenosis 


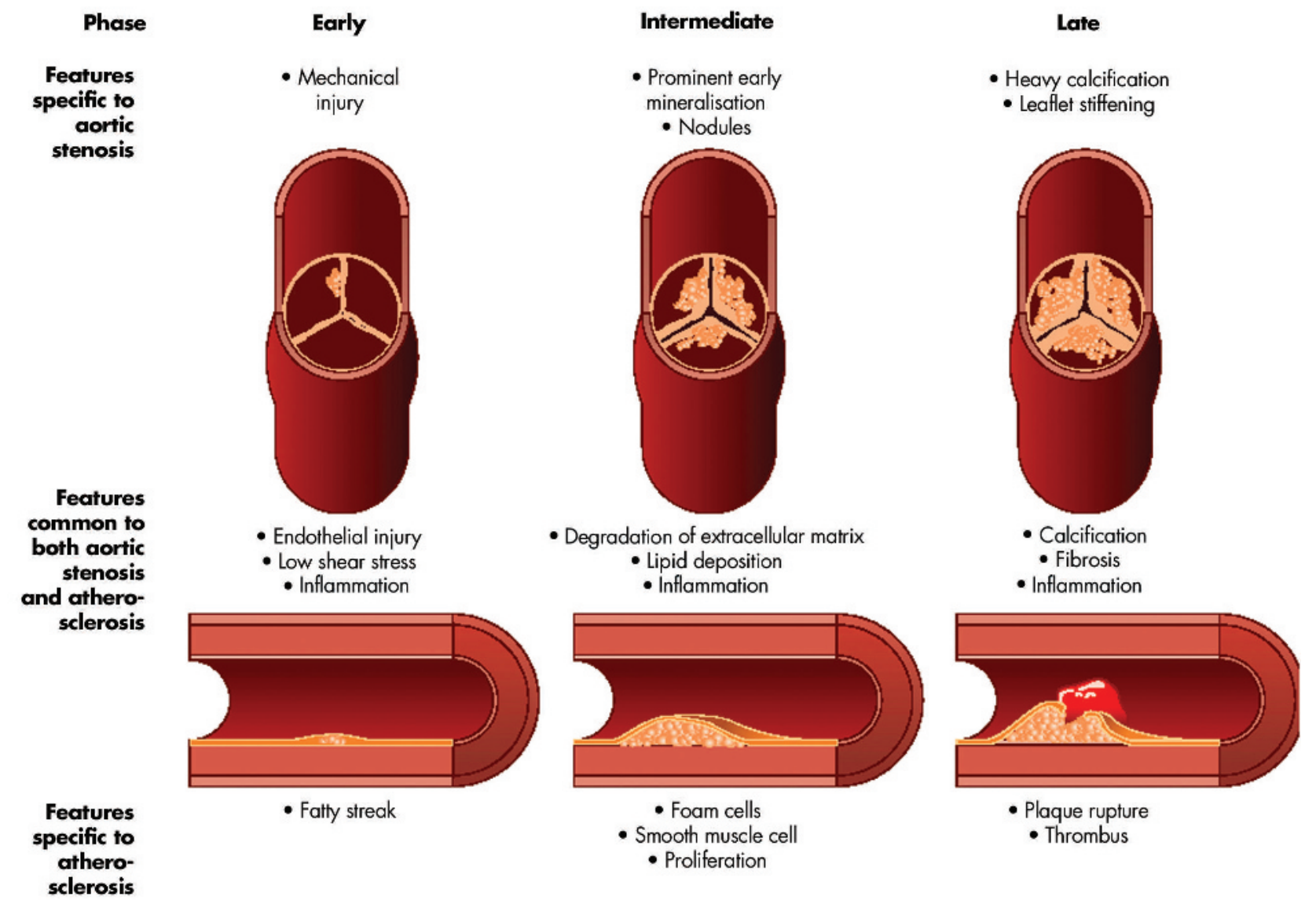

Figure 1 Common and specific pathogenetic features of aortic stenosis and atherosclerosis.

\section{Lipids}

Endothelial injury or disruption may allow lipids to penetrate the valvar interstitial tissue and accumulate in areas of inflammation. ${ }^{5}{ }^{6}$ The lipoproteins implicated in atherogenesis, including low density lipoprotein (LDL) and Lp(a) lipoprotein, are present in early aortic valve lesions and undergo oxidative modification. ${ }^{5}{ }^{6}$ These oxidised lipoproteins are highly cytotoxic and capable of stimulating inflammatory activity and mineralisation. ${ }^{7}$

\section{Inflammation and calcification}

Both macrophages and activated $\mathrm{T}$ lymphocytes are present in the early and advanced lesions of congenitally bicuspid and tricuspid aortic valves. ${ }^{4}$ Migration of these effector inflammatory cells appears to be mediated through increased endothelial expression of cellular adhesion molecules such as E selectin, intercellular adhesion molecule 1, and vascular cell adhesion molecule 1 . Once recruited into the subendothelium, the inflammatory cells release enzymes, such as matrix metalloproteinases, that degrade collagen, elastin, and proteoglycans within the aortic valve cusps.

Mineralisation is a characteristic of both atherosclerotic and aortic valve lesions and arises close to areas of inflammation. It is a prominent feature in calcific aortic stenosis and has been observed in early as well as advanced lesions. ${ }^{4}{ }^{8}$ Surgically excised valves have even shown areas of mature lamellar bone, haemopoietic marrow, and bone remodelling. ${ }^{8}$ Some features suggest the presence of an active highly regulated process closely resembling developmental bone formation. ${ }^{9}$

The initiation of mineralisation (nucleation) may be stimulated by the presence of cellular degradation products following apoptosis or by the presence of oxidised lipids. ${ }^{68}$ In vitro studies of cultured explants of stenotic valves have identified cells with osteoblastic characteristics capable of phenotypic differentiation and spontaneous calcification. Their origin is unknown but they may be derived from a pool of circulating immature pluripotent mesenchymal cells. These osteogenic cells or "calcifying valvar cells" express and produce a variety of regulatory bone matrix proteins including osteopontin and bone morphogenetic protein. ${ }^{8}$

\section{CALCIFIC AORTIC STENOSIS AND ATHEROSCLEROSIS}

Although the similarities with atherosclerosis were recognised as long ago as 1917, they were largely disregarded until recently. Histological studies have highlighted the common features but also confirmed differences in the cellular and mineral components of the two lesions.

Smooth muscle proliferation and lipid laden macrophages (or foam cells) are prominent features of vascular atheroma but are virtually absent from stenotic aortic valves (fig l). Furthermore, mineralisation occurs earlier and is a more extensive feature of aortic valve lesions than in atherosclerosis. ${ }^{4}$ These differences may, in part, explain why only $40 \%$ of patients with severe aortic stenosis have significant coronary artery disease and why the majority of patients with coronary artery disease do not have aortic stenosis. ${ }^{10}$ As the underlying pathological processes of the two conditions appear to be similar, other unknown factors are likely to influence the development of valvar as opposed to vascular lesions. ${ }^{11}$ 
A

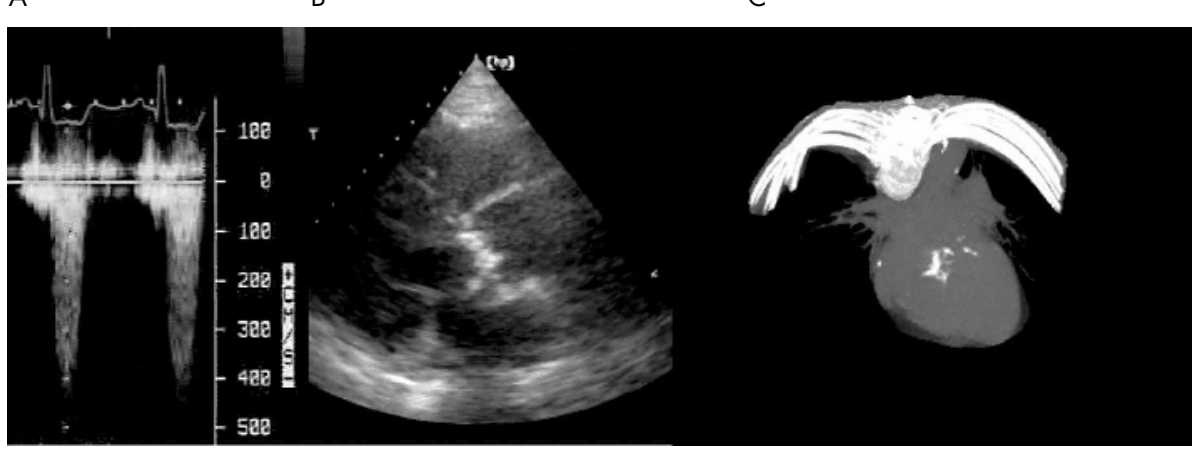

Figure 2 Clinical assessment by (A) Doppler echocardiography; (B) two dimensional echocardiography (parasternal short axis view); and (C) three dimensional computed tomography of the severity (lower panel) of aortic stenosis.

\begin{tabular}{lcccc}
\hline Aortic valve & Normal & Mild & Moderate & Severe \\
\hline Peak velocity $(\mathrm{m} / \mathrm{s})$ & $1-2$ & $2-3$ & $3-4$ & $>4$ \\
Peak gradient $(\mathrm{mm} \mathrm{Hg})$ & 0 & $16-36$ & $36-64$ & $>64$ \\
Mean gradient $(\mathrm{mm} \mathrm{Hg})$ & 0 & $<15$ & $15-50$ & $>50$ \\
Valve area $\left(\mathrm{cm}^{2}\right)$ & $>2.0$ & $2.0-1.2$ & $0.8-1.2$ & $<0.8$ \\
\hline
\end{tabular}

\section{PREDICTORS OF DISEASE PROGRESSION AND CLINICAL OUTCOME}

Patients with calcific aortic stenosis should be monitored regularly in the clinic for the development of symptoms: chest pain, breathlessness, and syncope. Progression of the valvar stenosis is principally monitored with Doppler echocardiography, although complementary clinical information can also be obtained from the ECG (left ventricular hypertrophy, heart block), two dimensional echocardiography, and computed tomography. This permits grading of the severity of the aortic stenosis (fig 2).

The natural history of aortic stenosis is for the valve gradient to rise inexorably with time. Disease progression and clinical outcome have been linked to many of the risk factors for calcific aortic stenosis (table 1). However, much of the evidence is conflicting and limited by the retrospective nature of the studies. The most consistent and strongest predictors of disease progression are severity of stenosis at baseline and degree of valvar calcification: the more severe the stenosis and the more heavily calcified the valve, the faster the rate of progression. ${ }^{12}{ }^{13}$ Clinical outcome is also influenced by the degree of valvar calcification, with nearly $80 \%$ of patients with moderate to severe calcification progressing rapidly ( $>0.3 \mathrm{~m} / \mathrm{s} /$ year) either to death or to aortic valve replacement within two years. ${ }^{13}$

\begin{tabular}{|l|}
\hline Table 1 Risk factors for calcific aortic stenosis \\
\hline Clinical \\
Age \\
Male sex \\
Smoking \\
Hypertension \\
Diabetes mellitus \\
Coronary artery disease \\
Chronic renal failure \\
Paget's disease \\
Hyperparathyroidism \\
Biochemical \\
Hyperlipidaemia* \\
Hypercalcaemia \\
Raised serum creatinine \\
\hline *Low density lipoprotein, Lp(a) lipoprotein. \\
\hline
\end{tabular}

\section{NOVEL TREATMENTS FOR CALCIFIC AORTIC STENOSIS}

Current management of patients with aortic stenosis comprises monitoring disease progression and ensuring patient awareness of the need for antibiotic prophylaxis against the relatively low risk of infective endocarditis. For those patients with severe symptomatic disease, aortic valve replacement is a priority with conventional medical treatment reserved for symptom control in inoperable cases. However, the majority of patients with aortic stenosis do not have symptoms or an indication for surgery. Are there any interventions that can halt or slow the progression of the disease process? Theoretically, anti-inflammatory and antiproliferative agents would be anticipated to alter the natural history of aortic stenosis. Statins and angiotensin converting enzyme (ACE) inhibitors are two commonly used treatments that have proven secondary preventative benefits in cardiovascular disease and exhibit some of these desirable antiinflammatory and antiproliferative properties.

\section{Statins}

Hydroxymethylglutaryl coenzyme A reductase inhibitors, or statins, are now well established in the primary and secondary prevention of coronary artery disease. Several studies have suggested that these drugs can cause regression of coronary artery disease and reduce the calcific volume of coronary plaques. ${ }^{14}$ Given the clinical association of calcific aortic stenosis with hyperlipidaemia and coronary artery disease, and the striking histological similarities with atheroma, the hypothesis that statins may have the potential to influence disease progression in aortic stenosis is intriguing. ${ }^{15}$

Recent retrospective studies have suggested that statins may delay disease progression in aortic stenosis (table $2^{16-22}$ ) through their lipid lowering and anti-inflammatory actions. ${ }^{16-19}$ These observational data should be interpreted with caution, since none of these studies were prospective randomised trials, serum LDL cholesterol concentrations did not correlate with disease progression, and the statin doses were small. There also appears to be some publication bias with studies reporting negative findings underrepresented in the literature..$^{21}$ 
Table 2 Summary of trials assessing progression of aortic stenosis by repeated echocardiography

\begin{tabular}{|c|c|c|c|c|c|c|c|}
\hline & \multicolumn{7}{|c|}{ Study and reference } \\
\hline & $\begin{array}{l}\text { Aronow } \\
\text { ef } a l^{16}\end{array}$ & $\begin{array}{l}\text { Novaro } \\
\text { ef }\left.a\right|^{17}\end{array}$ & $\begin{array}{l}\text { Bellamy } \\
\text { ef al }\end{array}$ & $\begin{array}{l}\text { Rosenhek } \\
\text { et al }{ }^{9}\end{array}$ & $\begin{array}{l}\text { Samal } \\
\text { ef a }{ }^{20}\end{array}$ & $\begin{array}{l}\text { Antonini-Canterin } \\
\text { et } a R^{21}\end{array}$ & Cowell et a ${ }^{22}$ \\
\hline Design & $\mathrm{RO}$ & $\mathrm{RO}$ & $\mathrm{RO}$ & $\mathrm{RO}$ & $\mathrm{RO}$ & $\mathrm{RO}$ & Prospective RCT \\
\hline Patients & 180 & 174 & 156 & 211 & 112 & 242 & 134 \\
\hline Patients taking statin & 62 & 57 & 38 & 50 & 55 & 121 & 65 \\
\hline Mean age (years) & 82 & 68 & 77 & 70 & 73 & 68 & 68 \\
\hline Mean follow up (months) & 33 & 21 & 44 & 24 & NA & 54 & 25 \\
\hline Total cholesterol (mmol/l) & NA & 5.5 & 5.8 & 5.8 & NA & NA & 5.7 \\
\hline $\begin{array}{l}\text { Correlation of progression with } \\
\text { LDL cholesterol }\end{array}$ & NA & Yes/no & No & No & Yes & NA & No \\
\hline Reduced progression with statin & Yes & Yes & Yes & Yes & No & No & No \\
\hline
\end{tabular}

Results of the SALTIRE (Scottish aortic stenosis and lipid lowering therapy, impact on regression) trial were recently reported. It was the first double blind randomised controlled trial of lipid lowering treatment in patients with calcific aortic stenosis. ${ }^{22}$ This trial of 155 patients showed that, although atorvastatin $80 \mathrm{mg}$ daily more than halved serum LDL cholesterol concentrations, it did not halt the progression or induce regression of the valve disease process as measured by Doppler echocardiography or helical computed tomography (fig 3). This occurred despite the association of atorvastatin with major reductions in serum $\mathrm{C}$ reactive protein concentrations (unpublished observations).

Given the data linking aortic stenosis with atherosclerosis and hypercholesterolaemia, why did intensive lipid lowering treatment not halt the progression of calcific aortic stenosis? One potential explanation is that, while these features may drive the initiation of aortic stenosis, disease progression may depend on other factors. The aortic valve is subjected to continuous dynamic mechanical stress, and leaflet plasticity and structure can have an overriding influence, such as with a bicuspid valve. Moreover, in contrast to atherosclerosis, aortic stenosis is associated with a virtual absence of smooth muscle cell proliferation and lipid laden macrophages, and is dominated by earlier and more extensive mineralisation. Decreasing the lipid pool and increasing the fibrous cap may be less relevant to the progression of aortic stenosis than it is for the reduction of atherosclerotic plaque rupture with statins in patients with coronary heart disease.

It may be argued that lipid lowering treatment is unlikely to influence disease progression in the presence of significant aortic stenosis. Patients with aortic velocities below $2.5 \mathrm{~m} / \mathrm{s}$ were excluded from the SALTIRE trial, and intervening at this earlier stage of the disease process may have been more beneficial. However, such patients do not commonly present to routine clinical practice and their identification would potentially require population screening. Moreover, the SALTIRE trial was unable to exclude a modest treatment benefit (a delay in disease progression of $<0.07 \mathrm{~m} / \mathrm{s} /$ year or $<5 \%$ aortic valve calcification/year). Although such modest reductions are unlikely to be meaningful in the majority of older patients, a small decrease in disease progression may be clinically important in younger patients with mild disease who may progress over many years. Indeed, a small preliminary observational study suggests that statins may reduce disease progression in patients with aortic sclerosis. ${ }^{21}$

Statin treatment of patients with aortic stenosis may confer secondary preventative benefits that are independent of its effects on the valve disease process because of the association between aortic stenosis and coronary artery disease. The SALTIRE trial was not powered to assess the benefits of lipid lowering treatment on cardiovascular end points, such as non-fatal and fatal myocardial infarction, but there was a trend in favour of reduced clinical events. Aortic stenosis and sclerosis may be important markers of occult vascular disease and thereby identify patients who would gain from the preventative benefits of statins. Larger clinical end point trials, such as the SEAS (simvastatin and ezetimibe in aortic stenosis) and ASTRONOMER (aortic stenosis progression observation: measuring effect of rosuvastatin) trials, will be able to address this issue.

Lastly, for many patients with aortic stenosis, the first symptom to develop is chest pain, and this precipitates the decision to replace the aortic valve. However, this may be driven by concomitant coronary artery disease rather than progression of valvar stenosis. Previous secondary prevention trials in coronary heart disease have reported a reduction in coronary artery bypass graft surgery rates. ${ }^{23}$ Thus, the larger clinical end point trials of statins in aortic stenosis may suggest a reduction in the rate of valve surgery, but this may be driven by patients with aortic stenosis who undergo combined aortic valve and bypass surgery for symptoms of angina pectoris. If statins truly reduce disease progression then a reduction in isolated aortic valve replacement would be anticipated.

\section{ACE inhibition}

There are several reasons to believe that ACE inhibitors may have a role in the management of patients with aortic stenosis. Firstly, in contrast to normal valves, sclerotic aortic valve tissues demonstrably express angiotensin II and ACE, which may contribute to valve inflammation, calcification, and disease progression. ${ }^{24}{ }^{25}$ Secondly, the pressure overload induced by aortic stenosis has several effects on the myocardium including left ventricular hypertrophy, apoptosis, and fibrosis. This may accelerate the left ventricular systolic and diastolic dysfunction associated with aortic stenosis. Lastly, blood pressure lowering indirectly reduces the pressure overload of the left ventricle and potentially reduces the mechanical stress and strain on the aortic valve.

Two preliminary observational studies with ACE inhibitors have produced conflicting results. In a retrospective analysis of 211 patients, Rosenhek et $a l^{19}$ found that progression of aortic stenosis was not delayed in patients maintained on ACE inhibitors. Furthermore, the presence of hypertension did not appear to influence the outcome. In contrast, O'Brien et $a^{24}$ found that ACE inhibitor treatment was associated with a $71 \%$ reduction in the progression of aortic valve calcification in 123 patients with aortic stenosis undergoing electron beam computed tomography. However, such retrospective observational data are difficult to interpret and the study findings have wide confidence intervals.

Historically, ACE inhibition was said to be contraindicated in patients with aortic stenosis. This has primarily been due to the concern of invoking profound peripheral vasodilatation that would result in haemodynamic compromise, collapse, and potentially death. However, patients with aortic stenosis 


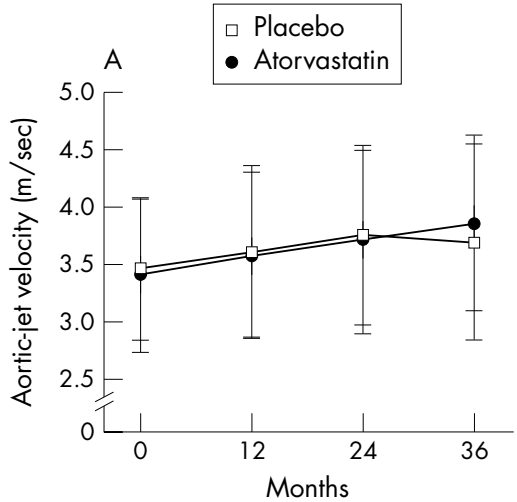

$\begin{array}{lllll}\begin{array}{llll}\text { Number of patients } \\ \text { Placebo }\end{array} & 77 & 69 & 55 & 30 \\ \text { Atorvastatin } & 77 & 65 & 60 & 34\end{array}$

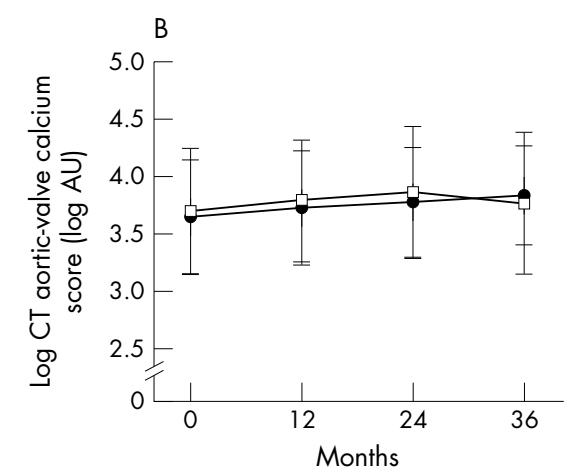

Number of patients

$\begin{array}{lllll}\text { Placebo } & 76 & 69 & 56 & 29\end{array}$

$\begin{array}{lllll}\text { Atorvastatin } & 77 & 64 & 60 & 34\end{array}$

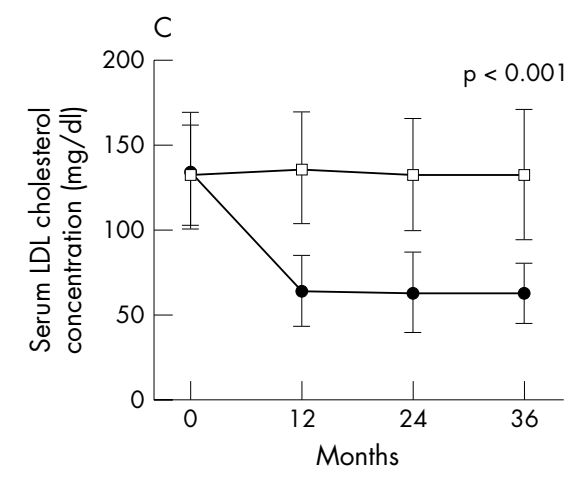

Number of patients

$\begin{array}{lllll}\text { Placebo } & 78 & 70 & 54 & 31 \\ \text { Atorvastatin } & 77 & 65 & 58 & 35\end{array}$

Figure 3 Effect of atorvastatin ( $80 \mathrm{mg}$ daily) on the progression of aortic stenosis and serum low density lipoprotein (LDL) concentrations. ${ }^{22}$ $\mathrm{AU}$, arbitrary units; CT, computed tomography. Copyright 2005 Massachusetts Medical Society. All rights reserved. Reproduced with permission of the publisher.

tolerate ACE inhibitors very well on initiation ${ }^{26} 27$ and many patients (about 30\%) with aortic stenosis are unknowingly established on such treatment without compromise. Indeed, the use of ACE inhibitors appears to confer long term survival benefit on patients considered to have a contraindication including those with aortic stenosis. ${ }^{28}$ The potential beneficial haemodynamic and cardiac effects of ACE inhibition are increasingly being recognised and warrant further study in patients with aortic stenosis. ${ }^{29}$

\section{CONCLUSIONS}

The need for an alternative to aortic valve surgery is highlighted by the increasing longevity of the population and rising prevalence of aortic stenosis. New therapeutic strategies to limit disease progression are needed to delay, and potentially avoid, the need for valve surgery.

Statins and ACE inhibitors are two potential and promising treatments that may have beneficial effects in patients with aortic stenosis. Statins are likely to reduce cardiovascular events rather than disease progression per se but may potentially be a valuable preventative treatment in these patients. However, we must await the results of ongoing large randomised controlled trials to define the role of statins.

The prejudice against the use of ACE inhibitors by patients with aortic stenosis is changing. ${ }^{23-26}$ We would argue that there is sufficient theoretical evidence to support the conduct of a randomised controlled trial to explore further its potential benefits. In the meantime, the cautious use of ACE inhibition by patients with concomitant hypertension, coronary heart disease, or heart failure seems appropriate.

\section{Authors' affiliations}

D E Newby, S J Cowell, N A Boon, Department of Cardiology, Royal Infirmary, Edinburgh, UK

Conflicts of interest declaration: The authors were involved in the SALTIRE trial funded by the British Heart Foundation with an additional educational grant award from Pfizer (UK) Limited and are participating in the SEAS study, which is sponsored by Merck Sharp and Dohme Limited.

\section{REFERENCES}

1 Stewart BF, Siscovick D, Lind BK, for the cardiovascular health study, et al. Clinical factors associated with calcific aortic valve disease. J Am Coll Cardiol 1997;29:630-4.

2 Otto CM, Lind BK, Kitzman DW, et al. Association of aortic-valve sclerosis with cardiovascular mortality and morbidity in the elderly. N Engl J Med 1999:341:142-7.

3 livanainen $\mathbf{A M}$, Lindroos $M$, Tilvis $R$, et al. Natural history of aortic valve stenosis of varying severity in the elderly. Am J Cardiol 1996;78:97-101.

4 Otto CM, Kuusisto J, Reichenbach DD, et al. Characterization of the early lesion of 'degenerative' valvular aortic stenosis: histologic and immunohistochemical studies. Circulation 1994:90:844-53.

5 O'Brien KD, Reichenbach DD, Marcovina SM, et al. Apolipoprotein B, (a), and $\mathrm{E}$ accumulate in the morphologically early lesion of 'degenerative' valvular aortic stenosis. Arterioscler Thromb Vasc Biol 1996; 16:523-32.

6 Olsson M, Thyberg J, Nilsson J. Presence of oxidised low density lipoprotein in nonrheumatic stenotic aortic valves. Arterioscler Thromb Vasc Biol 1999; 19:1218-22

7 Parhami F, Morrow AD, Balucan J, et al. Lipid oxidation products have opposite effects on calcifying vascular cell and bone cell differentiation: a possible explanation for the paradox of arterial calcification in osteoporotic patients. Arterioscler Thromb Vasc Biol 1997; 17:680-7.

8 Mohler ER, Gannon F, Reynolds C, et al. Bone formation and inflammation in cardiac valves. Circulation 2001;103:1522-8.

9 Demer LL. A skeleton in the atherosclerosis closet. Circulation 1995;92:2029-32.

10 Peltier M, Trojette F, Sarano ME, et al. Relation between cardiovascular risk factors and nonrheumatic severe calcific aortic stenosis among patients with a three-cuspid aortic valve. Am J Cardiol 2003;91:97-9.

11 Otto CM, O'Brien KD. Why is there discordance between calcific aortic stenosis and coronary artery disease? Heart 2001;85:601-2.

12 Otto CM, Burwash IG, Legget ME, et al. Prospective study of asymptomatic valvular aortic stenosis: clinical, echocardiographic, and exercise predictors of outcome. Circulation 1997;95:2262-70.

13 Rosenhek R, Binder T, Porenta G, et al. Predictors of outcome in severe, asymptomatic aortic stenosis. N Engl J Med 2000;343:61 1-7.

14 Callister TQ, Raggi P, Cooil B, et al. Effect of HMG-CoA reductase inhibitors on coronary artery disease as assessed by electron-beam computed tomography. N Engl J Med 1998;339:1972-8.

15 Mohler ER. Are atherosclerotic processes involved in aortic valve calcification? Lancet 2000;356:524-5.

16 Aronow WS, Ahn C, Kronzon I, et al. Association of coronary risk factors and use of statins with progression of mild valvular aortic stenosis in older persons. Am J Cardiol 2001;88:693-5.

17 Novaro GM, Tiong IY, Pearce GL, et al. Effect of hydroxymethylglutaryl coenzyme a reductase inhibitors on the progression of calcific aortic stenosis. Circulation 2001;104:2205-9. 
18 Bellamy MF, Pellikka PA, Klarich KW, et al. Association of cholesterol levels, hydroxymethylglutaryl coenzyme-A reductase inhibitor treatment and progression of aortic stenosis in the community. J Am Coll Cardiol 2002;40:1723-30.

19 Rosenhek R, Rader F, Loho N, et al. Statins but not angiotensin-converting enzyme inhibitors delay progression of aortic stenosis. Circulation 2004; 110:1291-5.

20 Samal AK, Berman AE, Kuruvanka TS, et al. Effect of statin therapy in the progression of moderate to severe calcific aortic stenosis. Circulation 2002; 106(suppl II):11640.

21 Antonini-Canterin F, Popescu BA, Huang G, et al. Progression of aortic valve sclerosis and aortic valve stenosis: what is the role of statin treatment? Ital Heart J 2005;6:119-24.

22 Cowell SJ, Newby DE, Prescott RJ, et al. A randomized trial of intensive lipid-lowering therapy in calcific aortic stenosis. N Engl J Med 2005;352:2389-97.

23 Heart Protection Study Collaborative Group. MRC/BHF heart protection study of cholesterol lowering with simvastatin in 20,536 high-risk individuals: a randomised placebo-controlled trial. Lancet, 20026, 360:7-22.
24 O'Brien KD, Probstfield JL, Caulfield MT, et al. Angiotensin-converting enzyme inhibitors and change in aortic valve calcium. Arch Intern Med 2005; 165:858-62.

25 Helske S, Lindstedt KA, Laine M, et al. Induction of local angiotensin Il-producing systems in stenotic aortic valves. J Am Coll Cardiol 2004;44:1859-66.

26 O'Brien KD, Zhao XQ, Shavelle DM, et al. Hemodynamic effects of the angiotensin-converting enzyme inhibitor, ramipril, in patients with mild to moderate aortic stenosis and preserved left ventricular function. J Investig Med 2004:52:185-91.

27 Chockalingam A, Venkatesan S, Subramaniam T, et al. Safety and efficacy of angiotensin-converting enzyme inhibitors in symptomatic severe aortic stenosis: symptomatic cardiac obstruction-pilot study of enalapril in aortic stenosis (SCOPE-AS). Am Heart J 2004;147:E19.

28 Ahmed A, Centor RM, Weaver MT, et al. A propensity score analysis of the impact of angiotensin-converting enzyme inhibitors on long-term survival of older adults with heart failure and perceived contraindications. Am Heart J 2005; 149:737-43.

29 Routledge HC, Townend JN. ACE inhibition in aortic stenosis: dangerous medicine or golden opportunity? J Hum Hypertens 2001;15:659-67.

\section{IMAGES IN CARDIOLOGY}

\section{A common cause of secondary hypertension: coarctation of the aorta}

A 16 year old male was referred to our department with hypertension refractory to medical treatment. He had recurrent episodes of headache. On physical examination, his blood pressures in right and left arms were 190/120 and 180/ $120 \mathrm{~mm} \mathrm{Hg}$, respectively. Also a systolic ejection murmur of grade $2 / 6$ was present at the left upper sternal border radiating to the interscapular region. Femoral pulsations were diminished. The ECG revealed left ventricular hypertrophy. The chest $x$ ray showed no pathology, but echocardiography revealed a bicuspid aortic valve, left ventricular hypertrophy, normal ascending aortic size, and an ejection fraction of $67 \%$ with normal systolic and diastolic dimensions. By using continuous wave Doppler, a $50 \mathrm{~mm} \mathrm{Hg}$ pressure gradient was assessed 3-4 cm from the left subclavian artery with the suprasternal notch view. Computed tomographic angiography (CTA) of the thoracic aorta was performed. CTA showed a significant coarctation of the thoracic aorta distal to the origin of the left subclavian artery (panel). It was decided to undertake surgical intervention to correct the problem.

Hypertension in teenagers and young adults is uncommon. As secondary causes are more commonly found in this age group than in older adults, aortic coarctation should be considered. Thus, palpation of femoral pulses and measurement of blood pressure in the limbs should be performed in every hypertensive young patient. Early diagnosis and treatment are essential for

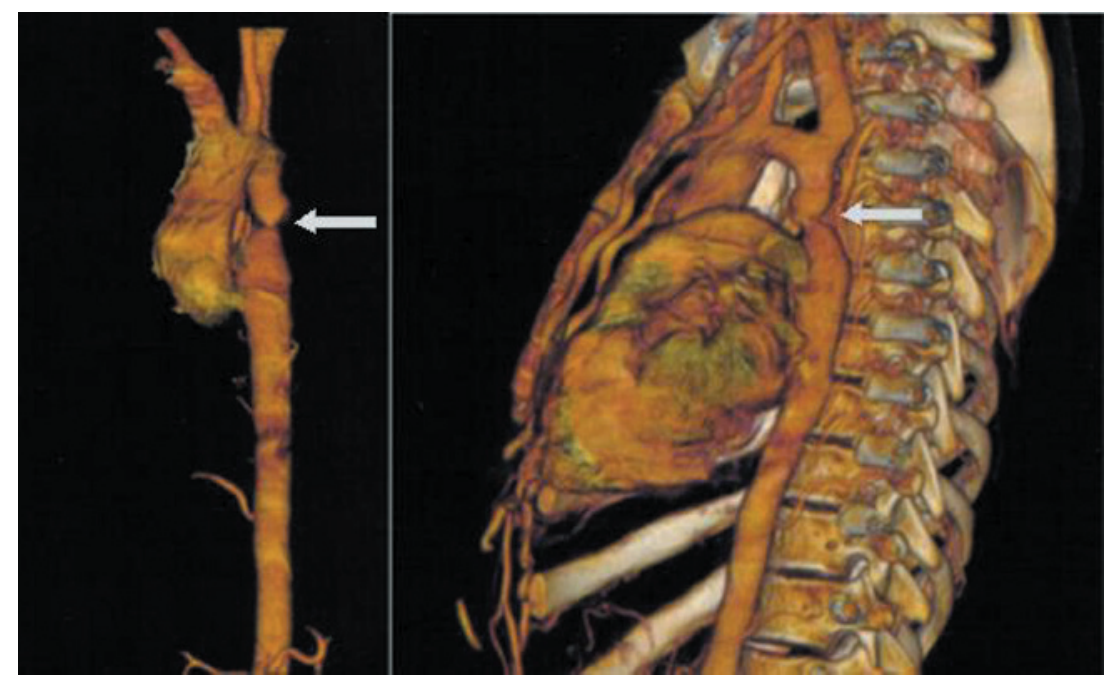

Computed tomographic angiography of the thoracic aorta showing a significant coarctation beyond the origin of the left subclavian artery (arrows).

the prevention of morbidity and mortality from premature cardiovascular complications. Surgical or percutaneous techniques should be performed together with medical treatment to prevent end organ damage. 